\title{
An Evaluation of Carotid Artery Intimal Medial Thickness and Insulin Resistance in Women with Polycystic Ovarian Syndrome
}

\author{
Dr.R.Manonmani ${ }^{1}$, Dr. S.Sumithra ${ }^{2}$ \\ ${ }^{1}$ Associate Professor ${ }^{2}$ Assistant Professor \\ (Department Of Obstetrics AndGynecology, Coimbatore Medical College, the Tamilnadu \\ Dr.M.G.R Medical University, India)
}

\begin{abstract}
This study aims at the evaluation of carotid artery intimal medial thickness and insulin resistance in women with polycystic ovarian syndrome. The age group ranged between 15 to 35 years. Main complaints were oligo-amenorhoea, obesity, hirsutism and infertility. Hyperinsulinemia with fasting insulin values $>30 \mu \mathrm{u} / \mathrm{ml}$ was detected in $62.5 \%$ of PCOS women in study group. The study group had significantly elevated mean fasting insulin level compared to the control. Fasting glucose / insulin levels <4.5 (insulin resistance) was present in $82.5 \%$ of study group. When compared with control the study group had carotid artery intimal medial thickness (IMT) significantly increased and intimal medial thickness positively correlated with fasting insulin levels and hirsutism. Further studies would help in improving the approaches to the management of insulin resistance in women with PCOS which helps in betterment of their quality of life by reducing the cardiovascular disease risk and improve their fertility outcomes.
\end{abstract}

Keywords: Carotid artery intimal medial thickness, Hyperinsulinemia, Insulin Resistance, Polycystic ovarian syndrome

\section{Introduction}

Polycystic ovarian syndrome is a heterogeneous, multisystem endocrinopathyseen in women of reproductive age with the ovarian expression of various metabolic disturbances and a wide spectrum of clinical features such as obesity, menstrual abnormalities and hyperandrogenism. Evidences suggest that Insulin resistance plays a central role in the pathogenesis of the reproductive as well as metabolic aberrations that characterize the syndrome and manifests itself in early adult life with gynecological symptoms. The syndrome is associated with numerous morbidities including infertility, obstetrical complications, obesity, type 2 diabetes mellitus, cardiovascular disease, mood and eating disorder. Early diagnosis of PCOS with close long term follow up and screening for cardiovascular diseases, diabetes, dyslipidemia and endometrial cancer are warranted. [1,2]

An opportunity exist for preventive therapy which should minimize the reproductive,metabolic and cardiovascular risks[3].The Carotid artery intimal medial thickness correlates strongly with future development of myocardial damage and stroke [4]. The current study is to evaluate hyperinsulinemia, insulin resistance in PCOS and its correlation with intimal medial thickness of carotid arteries which is a non-invasive marker of atherosclerosis.

To evaluate the significance of

\section{Objective}

a) Anthropometric measurements

b) Insulin resistance(fasting glucose /insulin ratio)

c) Carotid artery intimal medial thickness in PCOS

\section{Materials and Methods}

Patients who attended the gynecology OPD from May 2015 to April 2016 atCoimbatore Medical College Hospital with history and clinical manifestation suggestive of PCOS were analysed and those who fit in the inclusion criteria were taken for study numbering fifty.

A control group of fifty women studiedduring the same time period had spontaneous, regular cyclical menstruation and without any hyperandrogenicfeatures. All were euthyroid,euprolactinemic and normotensive.

3.1 Inclusion criterialess than 40 yearsUSG finding of polycystic ovariesHyperandrogenic featuresMenstrual disorders

3.2 Exclusion criteriaPrior endocrine or medical disorderPatients on hormone therapyPatients with chronic infection 
A detailed menstrual history, historyregardingobesity, acne, hirsutism and infertility were noted.Inparous women any previous history of preeclampsia, gestationaldiabetes and recurrent pregnancy loss was enquired.

\subsection{Physical examination}

A thorough clinical examination was done. Measurement of height was done with patient in barefoot,with the heels, buttocks and shoulder in contact with stadiometer heels were placed together with the medial malleoli touching each other. Weight was measured in standard calibrated weighing scale. Body mass index was calculated. Waist and hip measurements in cms were measured, waist was measured at the narrowest point between the rib cage and iliac crest. Hips were measured at the maximal points of the buttocks in $\mathrm{cms}$. Waist circumference of greater than $90 \mathrm{cms}$ and Waist/hip ratio $<0.85$ were taken as clinically significant.

Physical examination for evidence of hyperandrogenism was done which includes hirsutism,acne, temporal recession of hair growth and clitoromegaly. Hirsutism was assessed by Ferriman-Gallwayscoring, a score of 9 and above were diagnostic.

\subsection{Ultrasound of pelvis}

Patients were subjected to trans abdominal ultrasound with full bladder using linear transducer of frequency 3.75 MHz. Criteria used for diagnosing Polycystic ovaries were- follicles 12 or more ,measuring 2-9 $\mathrm{mm}$ in diameter and ovarian volume of more than $10 \mathrm{~cm}^{3}[5]$. Ultrasounds of the ovaries were done in transverse as well as in linear phase so as to obtain the length width and thickness of each ovary.Ovarian volume was calculated using the formula $0.523 x$ length $\mathrm{x}$ width $\mathrm{x}$ depth. All regularly menstruating women were scanned in the follicular phase and those with irregular menstruation and secondary amenorrhea were scanned at random.

\subsection{Blood parameters}

Venous blood for Fasting blood glucose, Fastinginsulin,TSH, and prolactin were taken in the morning after 12 hours of fasting. Fasting insulin level of more than $30 \mu \mathrm{u} / \mathrm{ml}$ and fasting glucose /insulin ratio of less than 4.5 were considered abnormal. Of the 50 study group 8 patients had elevated TSH level (>5 IU/L) and 2 patients had elevated Prolactin $(>30 \mathrm{ng} / \mathrm{ml})$ and hence 10 of them were excluded from further study and analysis.

\subsection{Intimal medial thickness measurement (IMT)}

The intimal medial thickness of carotid arteries was determined using a high resolution colourDoppler system having an electrical linear transducer midfrequency of $12 \mathrm{MHz}$.

The intimal medial thickness (IMT) was measured as distance from the leading edge of first echogenic line to the second echogenic line. The echogenic line represents the lumen intimal interface and the second line is produced by the collagen containing upper layer of the intima adventitia, at each longitudinal projection determination of IMT were conducted at the side of greatest thickness and two points $1 \mathrm{~cm}$ upstream and $1 \mathrm{~cm}$ downstream from the side of greatest thickness. The mean of six IMT measurements was used as representative of the subject.IMT value of more than $0.7 \mathrm{~mm}$ was considered as increased

\subsection{Statistical analysis}

Students $t$ testas appropriate was used for comparing mean values of selected variables.Pearson's correlation analysis was carried out determine the correlation of intimal medial thickness with variables of fasting insulin, fasting glucose/insulin ratio and hirsutism. A p value of less than 0.05 was considered significant

\section{Observation and Results}

Of the 40 patients in the study group the mean age was 24.35 years and in control group the mean age was 25.1 years. Most common presenting complaints were oligmenorrhoea(100\%), obesity $(65 \%)$, hirsutism(20\%), acne(18\%), infertility(15\%), secondary infertility(3\%), recurrent pregnancy loss(3\%). On comparing the BMI in the study group $42.5 \%$ patients were in overweight(BMI 25-30) and 17.5\%patients were in obesity range (BMI>30) whereas in control group $40 \%$ patients were in overweight range and none of them were obese. Among the 40 patients of the study group $17.55 \%$ had waist circumference more than $90 \mathrm{~cm}$ while all 40 patients in control group had waist circumference less than $90 \mathrm{~cm}$ which was statistically significant with $\mathrm{p}$ value $<0.05$. Fifty percent of the patients in the study group and $15 \%$ in the control group had waist/hip ratio of more than 0.85 and was not statistically significant.

Among the 40 patients in study group, 20 of them presented with hirsutism of which 9 had scoring of more than 9.

The study group of 40 patients, 25 of them (62.5\%) hadfasting insulin value $\geq 30 \mu \mathrm{u} / \mathrm{ml}$. The mean value in the study group was $42.11 \mu \mathrm{u} / \mathrm{ml}$, whereas the control group had a mean value of $20.04 \mu \mathrm{u} / \mathrm{ml}$. The mean fasting insulin values between study and control group were statistically significant with $\mathrm{p}$ value $<0.001$. 
In the study group 33 patients $(82.5 \%)$ had a fasting glucose/insulin ratio of less than 4.5 indicating insulin resistance. All in the control group (100\%) and 7 in the study group had fasting glucose/insulin ratio more than 4.5. this was statistically significant with a $p$ value of $<0.001$

Nine patients in the study group had IMT $>0.7 \mathrm{~mm}$, all patients in control group and $77.5 \%$ patients in study group had IMT $<0.7 \mathrm{~mm}$. The mean IMT measurements in study and control group were statistically significant with $\mathrm{p}$ value $<0.001$.

In the study group IMT and fasting insulin are positively correlated with correlation value of 0.52 . In control group also insulin level positively correlated with IMT with correlation of 0.295 the difference between these two correlation coefficient is statistically significant with p-value $<0.05$.

Intimal medial thickness is negatively correlated with fasting glucose/insulin ratio in study and control group with values of 0.48 and -0.21 respectively and is not statistically significant. IMT and hirsutism are positively correlated with correlation value of 0.727 and is statistically significant with p-value $<0.001$

\section{Discussion}

PCOS is a heterogenous syndrome with insults the metabolic milieu. Hyperandrogenism and chronic anovulation being the clinical expression of polycystic ovarian syndrome which is an aftermath of cascade of events resulting from hormonal imbalance to genetic predisposition. Women with PCOS are typically seen initially for medical attention because of their immediate concerns related to irregular bleeding, infertility and hirsutism.

Women with polycystic ovary syndrome are insulin resistant, have insulin secretory defects and have a high risk for glucose intolerance [6].Insulin resistance is one of the key insultswhichopensthedoor for comorbid complications. Additive factors like central obesity and genetic predisposition give flare to the presenting complaints.

Our study focuses some of the co-morbid complications occurring in PCOS. Central obesity documented by increase in waist circumference is a forerunner for the metabolic consequences and it is found to be significant among the study group. The central obesity and the resulting insulin resistance contribute to ovarian hyperandrogenism.[7]

The metabolic features are primarily related to underlying insulin resistance, which is now understood to play an important role in both the pathogenesis and long-term sequelae of PCOS[8,9].In spite of normal glucose tolerance test, altered glucoseinsulin ratio is quite evident in fasting sample which is a prelude to ongoing abnormality inglucosemetabolism and increased fasting insulin level in the study group indicates insulin resistancewhich may lead onto impaired glucose tolerance and frankdiabetes mellitus in future.

Carotid intima media thickness has been viewed as an early, subclinicalatheromatous change before gross plaque is seen or blood pattern are disturbed. Ultrasonography assessment of carotid arteries is a safe, noninvasive reproducible method of assessing the extent and severity of atherosclerosis. Measurement of carotid intima-media thickness (IMT) is considered an easy and reliable index of subclinical atherosclerosis, which is predictive of subsequent myocardial infarction and stroke[10]. Intimal medial thickness was found to be significantly greater in the study group than the control group.

PCOS patients present with an increased IMT independent of obesity and related directly to androgen excess this suggests that hyperandrogenism is associated with atherosclerosis and cardiovascular risk in these women[11].This study registers a positive correlation between fasting insulin with IMT and negative correlation with fasting glucose/insulin ratio and IMT. This signifies the importance of increase in prevalence of prothrombotic factors resulting in anatomical alterations especially in the intima of vessels amongst polycystic ovarian disease, which may be a forerunner in cardiovascular morbidity. At long-term follow-up a history of nonfatal cerebrovascular disease and cardiovascular risk factors including diabetes are more prevalent among women with polycystic ovary syndrome[12].

Our study shows IMT and hirsutism are positively correlated which is statistically significant.Thehyperandrogenemic phenotype of the syndrome may attenuate the consequences of the dysmetabolic phenotype on the vascular wall[10].

VI.

VII. Figures and Tables

Table 1Age distribution

\begin{tabular}{|l|l|l|l|l|l|}
\hline \multirow{2}{*}{ Age in years } & Study & Control & \multirow{2}{*}{ Total } \\
\cline { 2 - 5 } & Number & $\%$ & Number & $\%$ & \\
\hline
\end{tabular}


An evaluation of carotid artery intimal medial thickness and insulin resistance in women with ...

\begin{tabular}{|l|l|l|l|l|l|}
\hline$<20$ & 12 & 30 & 8 & 20.0 & 20 \\
\hline $21-25$ & 10 & 25 & 13 & 32.5 & 23 \\
\hline $26-30$ & 14 & 35 & 14 & 35.0 & 28 \\
\hline $31-35$ & 4 & 10 & 5 & 12.5 & 9 \\
\hline Total & 40 & 100 & 40 & 100 & 80 \\
\hline Mean \pm SD & $24.35 \pm 4.99$ & $25.1 \pm 4.71$ & \\
\hline
\end{tabular}

Table 2 Body mass index distribution

\begin{tabular}{|l|l|l|l|l|l|}
\hline \multirow{2}{*}{$\begin{array}{l}\text { Body } \\
\text { index }\end{array}$} & Study & Control & \multirow{2}{*}{ Total } \\
\cline { 2 - 5 } & Number & $\%$ & Number & $\%$ & \\
\hline$<20$ & 1 & 2.5 & 5 & 12.5 & 6 \\
\hline $20-24$ & 15 & 37.5 & 19 & 47.5 & 34 \\
\hline $25-30$ & 17 & 42.5 & 16 & 40 & 33 \\
\hline$>30$ & 7 & 17.5 & - & - & 7 \\
\hline Total & 40 & 100 & 40 & 100 & 80 \\
\hline Mean \pm SD & $26.46 \pm 5.17$ & $23.23 \pm 3.02$ & & \\
\hline
\end{tabular}

Table 3Waist circumference

$\mathrm{p}<0.05$

\begin{tabular}{|l|l|l|l|l|l|}
\hline \multirow{2}{*}{ Waist circumference } & Study & Control & \multirow{2}{*}{ Total } \\
\cline { 2 - 6 } & Number & $\%$ & Number & $\%$ & \\
\hline$<90$ & 33 & 82.5 & 40 & 100 & 73 \\
\hline $90-100$ & 4 & 10.0 & - & - & 4 \\
\hline$>100$ & 3 & 7.5 & - & - & 3 \\
\hline Total & 40 & 100 & 40 & 100 & 80 \\
\hline Mean \pm SD & $84.3 \pm 10.28$ & $79.27 \pm 6.33$ & \\
\hline
\end{tabular}

Table 4Waist /hip ratio

\begin{tabular}{|l|l|l|l|l|l|}
\hline \multirow{2}{*}{ Waist /hip ratio } & \multicolumn{2}{|l|}{ Study } & Control & \multirow{2}{*}{ Total } \\
\cline { 2 - 5 } & Number & $\%$ & Number & $\%$ & \\
\hline$<0.85$ & 20 & 50 & 34 & 85.0 & 54 \\
\hline$>0.85$ & 20 & 50 & 6 & 15.0 & 26 \\
\hline Total & 40 & 100 & 40 & 100 & 80 \\
\hline mean \pm SD & $0.819 \pm 0.059$ & $0.81 \pm 0.042$ & \\
\hline
\end{tabular}

Table 5Fasting insulin

\begin{tabular}{|l|l|l|l|l|l|}
\hline \multirow{2}{*}{$\begin{array}{l}\text { Fasting insulin } \\
\mu \mathrm{u} / \mathrm{ml}\end{array}$} & \multicolumn{2}{|l|}{ Study } & \multicolumn{2}{l|}{ Control } & \multirow{2}{*}{ Total } \\
\cline { 2 - 6 } & Number & $\%$ & Number & $\%$ & \\
\hline$<30$ & 15 & 37.5 & 40 & 100 & 55 \\
\hline$>30$ & 25 & 62.5 & - & - & 25 \\
\hline Total & 40 & 100 & 40 & 100 & 80 \\
\hline Mean \pm SD & $42.11 \pm 28.30$ & $20.04 \pm 4.91$ & \multicolumn{2}{|l}{} \\
\hline
\end{tabular}

$\mathrm{p}<0.001$

Table 6Fasting glucose/insulin ratio

\begin{tabular}{|l|l|l|l|l|l|}
\hline \multirow{2}{*}{$\begin{array}{l}\text { Fasting glucose } \\
\text { /insulin ratio }\end{array}$} & \multicolumn{2}{|l|}{ Study } & \multicolumn{2}{l|}{ Control } & \multirow{2}{*}{ Total } \\
\cline { 2 - 6 } & Number & $\%$ & Number & $\%$ & \\
\hline$<4.5$ & 33 & 82.5 & - & - & 33 \\
\hline$\geq 4.5$ & 7 & 17.5 & 40 & 100 & 47 \\
\hline Total & 40 & 100 & 40 & 100 & 80 \\
\hline Mean \pm SD & $2.81 \pm 1.45$ & $5.41 \pm 1.36$ & \\
\hline
\end{tabular}

$\mathrm{p}<0.001$

Table 7Intimal medial thickness of carotid arteries

\begin{tabular}{|l|l|l|l|l|l|}
\hline \multirow{2}{*}{ IMT(m) } & \multicolumn{2}{|l|}{ Study } & \multicolumn{2}{|l|}{ Control } & \multirow{2}{*}{ Total } \\
\cline { 2 - 5 } & Number & $\%$ & Number & $\%$ & \\
\hline
\end{tabular}


An evaluation of carotid artery intimal medial thickness and insulin resistance in women with ...

$\mathrm{P}<0.001$

\begin{tabular}{|l|l|l|l|l|l|}
\hline$<0.7$ & 31 & 77.5 & 40 & 100 & 71 \\
\hline$>0.7$ & 9 & 22.5 & - & - & 9 \\
\hline Total & 40 & 100 & 40 & 100 & 80 \\
\hline Mean \pm SD & $0.531 \pm 0.145$ & $0.386 \pm 0.062$ & \\
\hline
\end{tabular}

Table 8Correlation of IMT with variables

\begin{tabular}{|l|l|l|l|}
\hline Variables & Study & Control & p- value \\
\hline Fasting insulin & 0.522204 & 0.295477 & $<0.05$ \\
\hline hirsutism & 0.727853 & 0 & $<0.001$ \\
\hline Glucose /insulin ratio & -0.48861 & -0.21408 & NS \\
\hline
\end{tabular}

\section{Conclusion}

Polycystic ovary syndrome is a common and perplexing endocrine disorder of women in their reproductive years with a prevalence of up to $10 \%$ [13]. The current study brought to focus the presence of insulin resistance isrevealed as altered fasting glucose/insulin ratio in such women, especially amongst those whose waist circumference is more than $90 \mathrm{~cm}$.

Carotid intimal medial thickness a marker of ongoing prothrombotic event was found to be significantly increased in women with polycystic ovarian disease irrespective of the age of presentation. Women with PCOS are at a greater risk of premature atherosclerosis which emphasizes the importance of screening and monitoring cardio vascular risk factors in women with PCOS.[14, 15]

\section{References}

[1]. Goodarzi MO, Dumesic DA, Chazenbalk G, Azziz R. Polycystic ovary syndrome: etiology, pathogenesis and diagnosis. Nat Rev Endocrinol.2011; 7:219-231.

[2]. Robert J Norman, MD, Didier Dewailly, MD, Polycystic ovarian syndrome, The Lancet, 370,(9588), 25-31 August 2007, 685-697.

[3]. Rogerio A. Lobo, Enrico Carmina, The importance of diagnosing the polycystic ovary syndrome, Ann Intern Med. 132:2000, 983993

[4]. Grobbee DE, Bots ML, Carotid artery intima media thickness as an indicator of generalized atherosclerosis, J. Intern Med, 236 : 567-573, 1994.

[5]. BalenAH,Laven JS, Tan S1, Dewailly D, Ultrasound definition of Polycystic ovaries International consensus and definitions, human reprod. Update, 9(6), nov-dec 2003, p 505-514.

[6]. Richard S. Legro, Allen R. Kunselman, William C. Dodson and Andrea Dunaif,Prevalence and Predictors of Risk for Type 2 Diabetes Mellitus and Impaired Glucose Tolerance in Polycystic Ovary Syndrome: A Prospective, Controlled Study in 254 Affected Women,J.of clinical endocrinology and metabolism , 84 (1), 2009 pp. 165-169.

[7]. Héctor F. Escobar-Morreale, José L. San Millán, Abdominal adiposity and the polycystic ovary syndrome, Trends in Endocrinology \&Metabolism ,18( 7), September 2007, Pages 266-272.

[8]. H. J. Teede, S. Hutchison, S. Zoungas, C. Meyer,Insulin resistance, the metabolic syndrome, diabetes, and cardiovascular disease risk in women with PCOS , Endocrine, International Journal of Basic and Clinical Endocrinology,30(1)August 2006, , pp 45-53.

[9]. David A. Ehrmann, David R. Liljenquist, Kristen Kasza, Prevalence and Predictors of the Metabolic Syndrome in Women with Polycystic Ovary Syndrome, The Journal of Clinical Endocrinology \& Metabolism, 91(1):48 -53.

[10]. AndromachiVryonidou, AthanasiosPapatheodorou, Anna Tavridou, The Journal of Clinical Endocrinology \& Metabolism Volume 90, Issue 5January 14, 2009,p2740 -2746.

[11]. Manuel Luque-Ramírez, CovadongaMendieta-Azcona, Androgen excess is associated with the increased carotid intima-media thickness observed in young women with polycystic ovary syndrome, Hum. Reprod. 22 (12), 2007, p 3197-3203.

[12]. Roger Hart, Martha Hickey, Stephen Franks, Definitions, prevalence and symptoms of polycystic ovaries and polycystic ovary syndrome, Best Practice \& Research Clinical Obstetrics \&Gynaecology, Volume 18, Issue 5, Pages 669-824 (October 2004).

[13]. Sarah Wild, Tracey Pierpoint,Cardiovascular disease in women with polycystic ovary syndrome at long-term follow-up: a retrospective cohort study, Clinical endocrinology Volume 52, Issue 5 May 2000 ,Pages 595-600.

[14]. Michelle L. Meyer, Angela M. Malek, Robert A.Wild, Mary T. Korytkowski, Carotid artery intima-media thickness in polycystic ovary syndrome: a systematic review and meta-analysis, Human Reproduction Update, Vol.18, No.2 pp. 112-126, 2012.

[15]. Vural B, Caliskan E, Turkoz E, Kilic T, Demirci A. Evaluation ofmetabolic syndrome frequency and premature carotid atherosclerosisin young women with polycystic ovary syndrome. Hum Reprod.20 2005,2409-2413. 